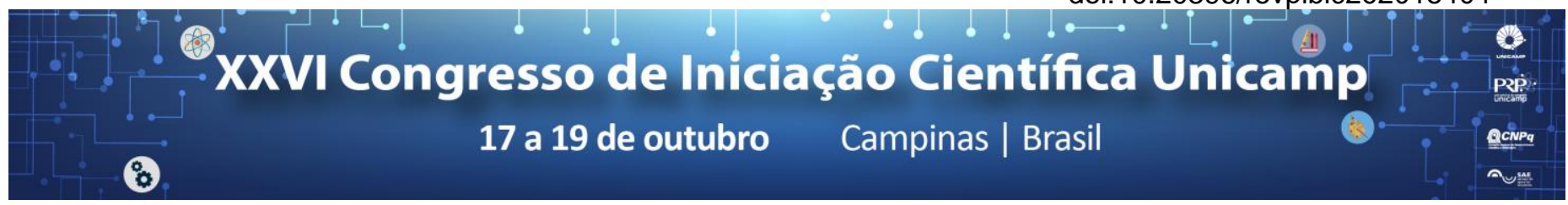

\title{
Um estudo sobre o híbrido simulação-otimização e seus impactos em sequenciamento de tarefas
}

\author{
Felipe A. Franceschini*, Prof. Dr. Anibal T. de Azevedo (orientador), Prof. Dr. Otávio G. Cabello (co-orientador)
}

\begin{abstract}
Resumo
Pesquisas na área de simulação-otimização (SO) têm ganhado espaço no meio acadêmico. A possibilidade de busca por melhorias (otimização) e a simulação de resultados otimizados motivam este trabalho a compreender aplicações para este híbrido. Resultados preliminares indicam melhorias no tempo médio das tarefas quando um sequenciamento otimizado é utilizado como semente para o simulador. O estudo propõe a combinação SO para além de simular cenários próximos à realidade, também otimizá-los de modo a economizar tempo, custos e desperdícios.
\end{abstract}

\section{Palavras-chave: \\ Simulação-otimização, pesquisa operacional, sequenciamento de tarefas}

\section{Introdução}

Simulação de sistemas e pesquisa operacional são temas comumente tratados como assuntos discordantes $^{1}$, porém, ambos estão presentes em aplicações de manufatura, coordenação de rotas de voos e serviços hospitalares ${ }^{2}$. Um dos principais objetivos da pesquisa operacional relaciona-se com a busca por soluções ótimas, enquanto na simulação de sistemas frequentemente estuda-se o efeito da variabilidade nos processos, tarefa que demandaria complexas análises matemáticas caso não existissem softwares para facilitar o estudo. Neste trabalho são propostos o estudo e a verificação da utilização de sistemas que combinam técnicas de otimização com simulação. Utilizando os tempos de processamento de algumas atividades de um escritório contábil localizado na cidade de Marília-SP, foi elaborada uma análise primária de alguns resultados da simulação-otimização (SO). Um sequenciamento de tarefas otimizado via pesquisa operacional (PO) foi utilizado como "semente" para o simulador. Na PO os dados são tempos únicos e não sofrem variações no tempo, enquanto em simuladores é possível estudar os efeitos dessa variação. A comparação dos resultados baseia-se no tempo mínimo/máximo de permanência das tarefas no sistema e também no tempo médio de processamento das tarefas.

\section{Resultados e Discussão}

A primeira análise realizada utilizou como regra de sequenciamento de tarefas a minimização do tempo de fluxo total. Segundo Arenales ${ }^{3}$, a minimização do tempo de fluxo total é dada pela regra SPT (shortest processing time), a qual sequencia as tarefas em ordem crescente de seu tempo de processamento. Dessa maneira, foi redigido um código no software Gusek para realizar o sequenciamento de tarefas aplicando a regra SPT, corroborando a teoria de Arenales. Contudo, o tempo de processamento do solver não foi viável, de modo que foi realizada, então, a redução da quantia de tarefas em análise para sete tempos de processamento, sendo o sequenciamento resultante utilizado como semente para a simulação no software FlexSim. Para efeitos comparativos preliminares foram realizadas simulações no FlexSim considerando que as tarefas seguiam uma distribuição uniforme com tempo médio informado pelo escritório e um desvio padrão de 5 sigmas. Três regras de ordenamento foram utilizadas sendo elas: ordenamento aleatório das tarefas, ordenamento por tempo crescente de processamento e ordenamento por tempo decrescente de processamento. Na tabela 1 são apresentados os resultados para cada simulação.

Tabela 1. Tempos simulado no FlexSim.

\begin{tabular}{|l|c|c|c|}
\hline $\begin{array}{l}\text { Ordenamento das } \\
\text { tarefas }\end{array}$ & $\begin{array}{c}\text { Tempo } \\
\text { médio } \\
\text { (min) }\end{array}$ & $\begin{array}{c}\text { Tempo } \\
\text { mínimo } \\
\text { (min) }\end{array}$ & $\begin{array}{c}\text { Tempo } \\
\text { máximo } \\
\text { (min) }\end{array}$ \\
\hline Crescente - SO & 104,98 & 19,33 & 397,63 \\
\hline Decrescente & 107,84 & 20,44 & 396,36 \\
\hline Aleatório 1 & 105,70 & 19,33 & 397,63 \\
\hline Aleatório 2 & 106,93 & 13,62 & 402,49 \\
\hline Aleatório 3 & 107,07 & 17,25 & 395,93 \\
\hline
\end{tabular}

Apesar de existirem variações no tempo mínimo e no tempo máximo de permanência da tarefa no sistema, o ordenamento crescente que representa a combinação de simulação-otimização possui o menor tempo médio de permanência no sistema. Esse resultado apresenta indícios de melhoria de performance em técnicas de simulação que fazem uso de resultados já otimizados e que podem ser comprovados em estudos futuros.

\section{Conclusões}

A melhoria obtida por meio da combinação simulaçãootimização, já estudada em outros artigos, não é trivial e demanda profunda reflexão metodológica. Este trabalho não demonstra, necessariamente, a melhoria obtida por uma combinação $\mathrm{SO}$, diante de sua simplicidade em relação a área de pesquisa, apenas apresenta os primeiros passos de estudo desta possibilidade de aplicação. Os resultados sugerem que o ordenamento crescente que representa a combinação SO possui o menor tempo médio de permanência no sistema. Artigos sobre o tema baseiam-se em aplicações práticas para o desenvolvimento da SO, desta forma acredita-se que seja necessária a aplicação com dados mais estruturados do que os obtidos neste trabalho.

\footnotetext{
1 FIGUEIRA, Gonçalo; ALMADA-LOBO, Bernardo. Hybrid simulationoptimization methods: A taxonomy and discussion. Simulation Modelling Practice and Theory, v. 46, p. 118-134, 2014.

2 VAN DIJK, Nico et al. Simulation and or (operations research) in combination for practical optimization. In: CONFERENCE ON WINTER SIMULATION, 37. Proceedings...Orlando: Winter Simulation Conference, 2005. p. 274-284.

${ }^{3}$ ARENALES, Marcos et al. Pesquisa Operacional. Rio de Janeiro: Elsevier;
} ABEPRO, 2011. 